\title{
O processo colaborativo do fazer a Ciência \& Saúde Coletiva
}

\author{
The collaborative process in the making of Ciência \& Saúde Coletiva
}

Raimunda Matilde do Nascimento Mangas (https://orcid.org/0000-0002-7284-7740) ${ }^{1}$

Telma Freitas da Silva Pereira (https://orcid.org/0000-0002-4185-4542) ${ }^{1}$

Luiza Pimenta Gualhano (https://orcid.org/0000-0002-4890-7985) ${ }^{1}$

Danúzia da Rocha de Paula (https://orcid.org/0000-0001-8966-4839) ${ }^{1}$

\footnotetext{
${ }^{1}$ Associação Brasileira de Saúde Coletiva (Abrasco). Av. Brasil 4036, sala 700 Manguinhos. 21040-361 Rio de Janeiro RJ Brasil. cienciasaudecoletiva@ fiocruz.br
}

\begin{abstract}
This paper presents the different stages of the editorial process of Journal Ciência \& Saúde Coletiva. Different processing work methods have been overcome over these 25 years, and others have been introduced. Each stage of this construction will be analyzed in-depth to discuss the "making" of an academic publication of such a large scale and complexity. The Journal Ciência \& Saúde Coletiva delves into each issue a theme in the field, addressing its cross-sectionality and complexity. This thematization ranges from 10 to 35 papers. Thirty-five papers are published monthly (thematic and free subjects), mostly in Portuguese, English, and Spanish, fulfilling the most prestigious national and international open -access databases' deadline requirements. In this making, one of the significant issues is funding because the crucial development institutions' support is very scarce.
\end{abstract}

Key words Science, Collective Health, Editorial process, Open science
Resumo Este artigo apresenta as diversas etapas do processo editorial da Revista Ciência \& Saúde Coletiva. Ao longo desses 25 anos diferentes modos de processar o trabalho foram sendo superados e outros foram sendo introduzidos. Cada etapa dessa construção será aprofundada com o objetivo de discutir "o fazer" cotidiano de uma publicação acadêmica de tamanha envergadura e complexidade. A Revista Ciência \& Saúde Coletiva aprofunda em cada edição um tema da área, tratando - o em sua transversalidade e complexidade. Essa tematização vai de 10 a 35 artigos, pois 35 artigos são publicados mensalmente (temáticos e temas livres), em sua maioria em português e inglês e espanhol, cumprindo as exigências de prazos das mais conceituadas bases de dados nacionais e internacionais de livre acesso. Nesse a fazer, um dos grandes problemas é o financiamento, pois é muito escasso - embora fundamental - o apoio das instituições de fomento.

Palavras-chave Ciência, Saúde Coletiva, Processo editorial, Ciência aberta 


\section{Introdução}

Neste artigo, propomo-nos a descrever e analisar as singularidades do processo editorial da Ciência \& Saúde Coletiva ao longo desses 25 anos, evidenciando a sua complexidade, as diferentes etapas do processo produtivo, desde a submissão do manuscrito, avaliação por pares, até a sua publicação e indexação nas bases de dados. Somos quatro autoras que conjuntamente e responsavelmente respondemos pela periodicidade e qualidade de cada edição que entregamos às mãos do leitor. Obviamente, somos fortemente ajudadas por outros atores que mencionaremos no decorrer deste artigo. Nosso trabalho é como o de pequenas formigas, em que cada uma carrega um pedaço do processo, sabendo que temos como objetivo o todo, ou seja, entregar a edição de cada mês. Tentaremos dar ao leitor o conhecimento do que fazemos, sabendo que não temos como comunicar-lhe o que excede e ultrapassa nossa tarefa: o amor, a dedicação, o estar envolvidas o tempo todo, a qualquer dia, hora e tempo. Por quê? Porque temos consciência de nossa missão.

A Ciência \& Saúde Coletiva (C\&SC) teve sua primeira edição publicada em 1996, sendo ela também a primeira revista da Associação Brasileira de Saúde Coletiva (Abrasco). Sua criação ocorreu em um contexto de consolidação da área da saúde coletiva e das reivindicações por um sistema universal de saúde ${ }^{1}$.

Historicamente, a periodicidade da Revista iniciou-se com dois números/ano, chegando a ser mensal a partir de 2011, tendo em vista seu sucesso editorial e o crescimento da demanda. Em cada uma de suas edições há, no mínimo, 10 a 12 textos temáticos e cerca de 20 a 25 outros sobre assuntos variados do campo da saúde coletiva, além de opiniões e resenhas. Atualmente, divulgam-se 35 artigos por edição. Desde 2014, o periódico publica a versão impressa em português e a versão completa online, na base de dados SciELO e em outras bases de indexação, em português e inglês. No último quinquênio, Ciência \& Saúde Coletiva recebeu em média 4.000 originais/ano. Em 2019, foram divulgados mais de 400 artigos e mais de 1.800 investigadores tiveram oportunidade de expor suas investigações e suas reflexões sobre a área de saúde coletiva.

Houve, no decorrer da história da Revista, um crescimento visível de participação de autores nacionais e internacionais tanto na recepção de originais como no número de artigos publicados. O periódico recebe diversas colaborações de pesquisadores de países de língua inglesa, espanhola e francesa. Atualmente, a Revista está classificada com a categoria A3 no sistema Qualis/Capes. E mantém seu propósito de enfrentar os desafios, buscar a consolidação e promover uma permanente atualização das tendências do pensamento e das práticas na saúde coletiva, em diálogo com a agenda contemporânea da Ciência \& Tecnologia.

A fim de oferecer maior compreensão do processo editorial na Ciência \& Saúde Coletiva apresentamos ao leitor uma subdivisão das etapas do processo editorial: (1) Submissão e avaliação de artigos; (2) Seleção de artigos, editoração e publicação; e (3) Impressão, indexação e divulgação.

\section{Submissão e avaliação de artigos}

A forma de recepção dos artigos foi se modificando ao logo dos anos. Inicialmente os autores encaminhavam seus originais através de correspondência escrita em três vias para a Editoria da Revista. Esse material devia ser acompanhado por um disquete com o arquivo completo. $\mathrm{O}$ artigo, em suas várias vias, era encaminhado aos avaliadores e seu parecer, e devolvido também através dos Correios. E ainda, esperavam-se os documentos assinados sobre originalidade e licença para publicar.

Em 2005, o volume de manuscritos recebidos por Correios era de 263. As constantes idas e vindas de um artigo, durante a avaliação, atrasava em demasia sua divulgação. Além da demora para se poder publicar, outros fatores dificultavam o processo editorial, sendo os mais comuns: falta de um modelo de gestão para acompanhamento das etapas de avaliação, altos custos de manutenção do periódico e, o que ainda ocorre, baixíssimos investimentos dos órgãos de fomento na divulgação científica ${ }^{2}$. Isso fazia com que a Revista dançasse sempre na corda bamba: aumento da demanda e dificuldades para viabilizar sua publicação. Parece milagre, mas nós nunca atrasamos sua entrega aos leitores!

Para atender a uma demanda cada vez maior e acompanhar o progresso tecnológico nos processos de acompanhamento editorial, em 2006, a Revista criou seu sistema próprio e informatizado de submissão e avaliação de artigos em uma página na internet: www.cienciaesaudecoletiva. com.br. Esse novo modelo de relação com os autores impulsionou a submissão dos originais e nesse ano foram recebidos 545 manuscritos, o que representou um aumento de mais de $100 \%$.

Neste fluxo, a média de tempo tomado entre submissão, avaliação, aprovação e divulgação de um artigo passou a ser de oito meses. Mas nes- 
se mesmo ano, outra inovação foi introduzida. Abrimos um espaço online no site da Revista destinado a divulgar, de imediato, no máximo em 24 horas, cada texto depois de aprovado, E no mesmo espaço era indicada a forma de citação caso o artigo fosse já mencionado. Com esse expediente - que perdura até hoje - pretendemos dar visibilidade aos trabalhos aprovados que aguardavam publicação impressa e indexação nas bases de dados, sendo seu único problema, no momento, não podermos atribuir o DOI aos mesmos. Com o processo de informatização do fluxo de submissão e de avaliação, observamos um crescimento exponencial da demanda. Chegamos a 2013 recebendo 2.800 artigos/ano.

Em 2014, a Ciência \& Saúde Coletiva migrou do seu sistema próprio de gestão de artigos para o ScholarOne Manuscripts, oferecido pelo SciELO. Esse se constitui numa plataforma eletrônica de editoração de periódicos científicos, utilizada mundialmente, e pertence à Clarivate Analytics (Grupo Web of Science). A ScholarOne Manuscripts é uma plataforma internacional que padroniza o processo de editoração dos grandes periódicos nacionais e internacionais. Ela possibilita a transparência em todas as etapas do processo de avaliação de um artigo pelos autores e demais colaboradores ${ }^{2}$. Entrar nessa plataforma exigiu maior grau de profissionalização da equipe editorial, dos editores chefes e dos colaboradores para que todos dominassem os novos processos. O ScholarOne permite a pré-análise dos artigos que chegam ao sistema, recusa imediata por falta de padronização, submissão, encaminhamento para avaliação por pares, aprovação, aprovação sob condição ou recusa ${ }^{3}$.

A adesão da Revista à plataforma ScholarOne tem contribuído para sua internacionalização o que ocorreu pari passu com o aumento da representação de colaboradores internacionais no Conselho de Política Editorial do Conselho Editorial. Além do corpo de revisores da Revista, pareceristas ad hoc de vários países têm contribuído para a qualidade de originais, sendo os principais oriundos de Portugal, Espanha, México, Colômbia, Argentina, Chile, Uruguai, Peru, Venezuela, Cuba, Estados Unidos, Canadá, Reino Unido e França.

Tendo em vista o incremento da demanda à Revista, desde 2014, foi ampliado também o grupo de especialistas que compõe a equipe de "Editores Associados": são 19 pesquisadores que representam suas respectivas subáreas. Sobre eles recai a maioria dos encaminhamentos para revisão por pares, a partir dos três Editores Chefes que lideram o processo de avaliação. Essa organização se entende porque atualmente o número de originais postados na página ultrapassa, como já dito, 4.000/ano.

É importante ressaltar que a avaliação de um manuscrito na Revista pode demorar até 90 dias, mas, como já mencionado, assim que aprovado, o artigo é imediatamente inserido no site da revista no espaço Ahead of Print e o autor pode informar aos colegas e às instituições que seu trabalho já está divulgado. Isso impacta positivamente o autor e o processo de comunicação científica.

\section{Seleção de artigos, editoração e publicação}

O trabalho de edição tem início com a seleção dos artigos que irão compor uma edição. Vale ressaltar que a Revista Ciência \& Saúde Coletiva publica edições temáticas desde sua origem. A ideia de fazer uma revista com essa peculiaridade vem do propósito da Abrasco de promover, aprofundar e socializar discussões acadêmicas e debates interpares sobre assuntos considerados importantes e relevantes, acompanhando o desenvolvimento histórico da saúde pública do país. Existe hoje um reconhecimento entre os diversos atores que compõem a área sobre a relevância dessa especificidade, principalmente para a formação dos profissionais que fazem pós-graduação stricto e lato sensu, para fundamentação de pesquisas, para debate de políticas públicas e de gestão do setor e para informar a opinião pública. Um escopo inegociável da revista é contribuir para o aprimoramento do Sistema Único de Saúde.

Um número temático geralmente contém as seguintes categorias de trabalhos científicos: (1) dez artigos inéditos sobre o assunto em seus mais diferentes aspectos, devendo ser quase todos ou na totalidade, frutos de pesquisa; (2) algum texto de opinião que contemple o livre pensar de alguém importante da área e que tem domínio intelectual sobre o tema, o que pode ser substituído por uma entrevista; (3) uma ou mais resenhas de livros sobre a questão.

Os números temáticos atualmente entram na pauta em três modalidades de demanda:

- Por Termo de Referência enviado por professores/pesquisadores da área de saúde coletiva, espontaneamente. Ou igualmente, por coordenadores de pesquisa inédita e abrangente, relevante para a área, sobre resultados apresentados em forma de artigos, dentro dos moldes já descritos. O termo de referência pode ser sugerido pelos editores-chefes, quando consideram a urgência 
de determinado assunto. Nessas duas primeiras modalidades, o Termo de Referência é avaliado em seu mérito científico e relevância pelo Comitê de Política Editorial.

- Por Chamada Pública anunciada na página da Revista, e sob a coordenação de Editores Convidados. Essa Chamada se constitui num processo de indução da produção de conhecimentos de temáticas consideradas de relevância, o que é feito por meio de anúncio no próprio site da Revista. Em geral, o processo das Chamadas funciona assim: pesquisadores da área fazem uma proposta por meio de um Termo de Referência que justifica a demanda e propõe a receber dados de estudo e pesquisas sobre determinado tema, visando aprofundá-lo. Nesse caso, os manuscritos são submetidos através de e-mail disponível durante determinado período. A avaliação de artigos exige um esforço coletivo dos editores responsáveis pelo número e grupo de editores associados e editores-chefes, depois do processo de recepção dos originais eles entram no sistema ScholarOne e são submetidos ao processo de avaliação por pares.

- Por Organização Interna dos próprios editores-chefes, reunindo sob um título pertinente, artigos de livre demanda sobre algum tema específico, dentro dos critérios já descritos. Nessa modalidade, o primeiro passo é observar no banco de artigos aprovados os temas mais recorrentes. Atualmente, o banco de artigos aprovados é composto por mais 300 artigos dos mais diversos temas da saúde coletiva.

A editoração da revista Ciência \& Saúde Coletiva possui vários serviços e processos de trabalhos diferenciados, entre eles: a tradução para inglês, a revisão de português, a padronização, a editoração de texto, a impressão, a marcação XML e a indexação nas bases de dados. Esses são todos serviços e processos de trabalho realizados numa dinâmica que inclui vários atores, por vezes simultânea e por vezes paralelamente, o que torna sua complexidade ainda maior e responsabiliza a todos e a cada um. É um fazer que é individual de cada serviço especializado, mas, ao mesmo tempo é coletivo no seu conjunto, exigindo engajamento de todos para que o produto - a edição - fique perfeita. Ou seja, quando fica pronta uma nova edição, ela é fruto do espírito colaborativo e da cumplicidade dos atores envolvidos: autores, revisores, tradutores, editores e equipe editorial.

Como existe um empenho da Revista na divulgação internacional da produção dos autores, dos 35 manuscritos inéditos publicados em cada edição, cerca de 70\% a 75\% são traduzidos para o inglês. Isso significa que a equipe de editoração trabalha com quase duas edições mensais: uma em português, e outra em inglês. Sabemos que muitos periódicos brasileiros já publicam apenas em inglês. Mas Ciência \& Saúde Coletiva é um periódico produzido pela Abrasco e costuma ser lido também por estudantes de graduação, pessoas da comunidade e profissionais que atuam nos serviços de saúde. Por isso, a edição em português faz parte do compromisso da Revista, embora sua elaboração bilíngue seja um desafio e um trabalho duplo, parte de nosso compromisso.

\section{Impressão, indexação e divulgação científica}

Hoje a Ciência \& Saúde Coletiva imprime 300 exemplares mensais, e de acordo com a demanda e recursos disponíveis, algumas edições têm uma tiragem maior. A tendência futura será, como o faz grandes editoras como a Oxford, imprimir apenas sob demanda. A impressão exige outros processos próprios como a confecção de prova de prelo, emendas e ajustes e, por fim, a distribuição. Atualmente, para realizar a impressão, a Ciência \& Saúde Coletiva conta com o apoio da Fundação Oswaldo Cruz que desde 2011 dá suporte à sua impressão e alguns serviços de editoração.

Até chegar às bases de dados, a Revista passa por um processo tecnológico que tem etapas específicas como marcação XML e indexação propriamente dita. Ela está indexada em 22 bases de dados nacionais e internacionais. Para que isso ocorra, Ciência \& Saúde Coletiva segue à risca os cinco critérios de desempenho para sua manutenção na coleção SciELO: pontualidade na entrega dos arquivos para indexação; indicador de uso de periódico através de downloads; indicador de impacto por citação de artigo; indicador de influência dos artigos na web; indicador de internacionalização de periódicos; e elaboração de um relatório anual de desempenho ${ }^{4}$.

Desde o seu surgimento, Ciência \& Saúde Coletiva está alinhada ao movimento mundial da comunicação científica de livre acesso. E concernente com seus princípios, participa do movimento da chamada "ciência aberta" que preconiza: aceitação de manuscritos depositados em servidores de preprints; abertura progressiva do processo de avaliação por pares; abertura e compartilhamento de dados como parte do processo de submissão de artigos. A partir de 2019, o ORCID (Open Researcher and Contributor ID) dos autores já constam em todos os artigos publica- 
dos e passaram a ser aceitos artigos divulgados em preprints ${ }^{5}$.E em 2021, em cada edição serão divulgados os nomes dos pesquisadores que contribuíram para a avaliação do material nela publicado.

Não poderíamos deixar de mencionar a entrada de Ciência \& Saúde Coletiva nas redes sociais como o Facebook em agosto de 2014, no Twitter em setembro de 2015 e Instagram a partir de 2019. Inicialmente, as postagens eram muito simples, até que em 2019 passamos a contar com a atuação profissional de um editor de comunicação e divulgação científica, que está à frente da divulgação nas redes sociais e do contato com a imprensa. Publicamos também press release de cada uma das edições, no Blog SciELO em Perspectiva, nas redes sociais e em nosso site.

O Fator de Impacto (FI) da C\&SC vem subindo e segundo o índice Journal Citation Reports (JCR), da Web of Science, a Revista Ciência \& Saúde Coletiva em 2016 chegou ao FI: 0,780 e em 2019 atingimos o FI: 1,008. Nos últimos três anos, ela alcançou o $1^{\circ}$ lugar no ranking do Google Scholar, acima de todos os periódicos científicos brasileiros de todas as áreas. Essa história de sucesso de uma publicação nacional tem como mérito a transparência nos processos de avaliação, o apoio da Fundação Oswaldo Cruz, das instituições de fomento como CNPq/CAPES e FAPERJ, e do trabalho colaborativo e voluntário de tantos nomes da ciência brasileira e do traba- lho incansável da equipe editorial e de seus editores-chefes.

Os desafios que virão pela frente são muitos e teremos que enfrentá-los. Mas nestes 25 anos já temos uma bela história, temos orgulho dela e de podermos continuar escrevendo-a com muita dedicação, profissionalismo e superação em prol da divulgação científica brasileira. Deixamos uma nota especial: embora somos quatro as que conduzimos todo o processo editorial, devemos muita gratidão a todos que trabalham conosco: em primeiro lugar, à Adriana Fontes que há mais de 13 anos é nossa diagramadora e parceira fiel; Marcelo Afonso, nosso revisor de português há mais de 10 anos; Derrick Phillips e Jean Pierre Barakat que vestiram a camisa da Revista e são nossos tradutores para o inglês; Livia Marinho que já chegou entusiasmada com o trabalho e é nossa companheira e também revisora de português, Neyson Freire, que cuida da comunicação e divulgação científica com muita competência e deu um novo impulso à Revista nessa área. E Karine Oliveira, nossa aluna de iniciação científica que cada vez mais se introduz no processo de divulgação científica. Além da GN1, que nos presta um serviço profissional de marcação XML, nossa imensa gratidão também vai para o SciELO. O SciELO além de todos os predicados que tem, é nossa fonte de conhecimento, de impulsionamento e de certificação de que estamos no caminho certo.

\section{Colaboradores}

Todas as autoras participaram igualmente de todas as etapas de elaboração do artigo e leram e aprovaram a versão final. 


\section{Referências}

1. Minayo MCS. Ciência \& Saúde Coletiva no contexto nacional e internacional da divulgação científica. Cien Saude Colet 2015; 20(7):2013-2022.

2. Bomfá CRZ, Castro JEE. Desenvolvimento de revistas científicas em mídia digital: o caso da Revista de Produção online. Cien Inf 2004; 33(2):39-48.

3. Wegner W, Kaiser DE, Goes GO, Tavares JP, Glanzener $\mathrm{CH}$, Gouveia HG, Alite GB. Profissionalização da editoração de periódicos científicos: desafios da gestão de manuscritos na implantação do Scholar One manuscritos. Rev Gaúcha Enferm 2017; 38(4):e81448.

4. Scientific Electronic Library Online (SciELO). Critérios, política e procedimentos para a admissão e a permanência de periódicos científicos na Coleção SciELO Brasil. São Paulo: SciELO; 2014.

5. Minayo MCS, Gomes R, Silva AAM. 25 anos de ciência para construção do SUS. Cien Saude Colet 2020; 25(3):780-780.

Artigo apresentado em 30/07/2020

Aprovado em 05/08/2020

Versão final apresentada em 07/08/2020 